\title{
Deriving Niger's Demographic and Education Future to 2062 with Stakeholders: Which Results?
}

\author{
Anne Goujon $^{1}$ (D) Guillaume Marois ${ }^{1,2} \cdot$ Patrick Sabourin ${ }^{1}$
}

Received: 29 November 2019 / Accepted: 10 April 2020 / Published online: 22 April 2020

(c) The Author(s) 2020

\begin{abstract}
Niger has the fastest population growth in the world while being among the least developed countries. With an average fertility above seven children per woman in the last decades, rapid population growth will continue in the medium to long term representing a planning challenge for Niger's development whose actual population is likely to double within the next two decades. At the same time, socio-economic variables whether in terms of health, wealth, and education levels are lagging behind, also relatively to many countries in sub-Saharan Africa. While both demographic and education variables occupy a central position in the government strategy, they are not necessarily linked. However, the future of Niger will largely be a reflection of its ability to meet both challenges. Within a project piloted by the Ministry of Planning and funded by the United Nations Children's Fund, we have derived together with local experts and stakeholders narratives about the possible future of Niger. These were further translated into five scenarios with assumptions about different future paths of demographic and educational development for Niger that were used to project the population, also at sub-national level, using multi-state population projection models with the aim to inform policy. This article reports some projection results related to educational and demographic developments.
\end{abstract}

Keywords Niger $\cdot$ Population projections $\cdot$ Education $\cdot$ Fertility $\cdot$ Policy development

Anne Goujon

goujon@iiasa.ac.at

Guillaume Marois

marois@iiasa.ac.at

Patrick Sabourin

sabourin@iiasa.ac.at

1 Wittgenstein Centre for Demography and Global Human Capital (Univ. Vienna, IIASA, VID/ OEAW), International Institute for Applied Systems Analysis, Schlossplatz 1, 2361 Laxenburg, Austria

2 Asian Demographic Research Institute (ADRI), Shanghai University, Shanghai, China 


\section{Introduction}

Niger has the fastest population growth in the world while being among the least developed countries. According to the last census of 2012 (Census 2012), the population of Niger was 17.1 million inhabitants, and had been growing at an average annual rate of $4.1 \%$ since the previous census of 2001 (10.8 million), while in 1977, the country only had 5.1 million inhabitants. This sharp increase has been especially caused by fertility that has been on average above seven children per woman at least since the 1950s. Nowadays, Niger has the highest fertility rate in the world (United Nations 2019). This high fertility, coupled with a decline in mortality rates, especially of children under 5 years of age (the under-five mortality rate declined from 318 to 127 deaths per 1000 live births between 1992 and 2012 (Spoorenberg and Issaka Maga 2018) will generate a further substantial and inevitable increase in the population in the medium term to long term, which represents a planning challenge for Niger's development. This is why demographic variables occupy a central place, both in recent strategy documents of the government. ${ }^{1}$

At the same time, the social, economic, environmental and technological development of the country requires that the youth population receive a quality education. However, the high population growth complicates the challenge of education for all and the enhancement of all social sectors in general because of the ever-increasing needs. According to the latest census, In 2012, 77\% of the working-age population (aged 15-64) had not received any formal education and 5\% an incomplete primary education-for women, the respective rates were $82 \%$ and $4 \%$.

This research brief presents the main results of a project looking at demographic and education future to 2062 in Niger (also at sub-national level), that also resulted in an exhaustive report (Goujon et al. forthcoming). The project was conducted in partnership with the ministry of Planning of Niger and was funded by the United Nations Children's Fund (UNICEF). The project assumes the importance of education for human development and its impact on demographic behaviour and shows through multidimensional projections of population by level of education the different faces that Niger could take in the future. Indeed, much research, especially since the 1980s, has shown that women's education is strongly correlated with fertility trends, also in sub-Saharan Africa (Kraval 2002; Bongaarts 2010). Not only do most educated women have fewer children in their lives compared to those who have received less or no education, but also increasing levels of education would most likely translate into fertility decline, especially during demographic transition. Moreover, education is negatively related to mortality, and in particular women's education to infant and child mortality. In Niger, women with a secondary or higher education had on average 3 children less than women with a primary education or less (4.9 children vs. 7.9 children) over the 2009-2012 period. As well, the mortality rate was $38 \%$ higher for infants born to a woman without education compared to those born to a woman with a secondary education or more (Niger DHS 2012).

\footnotetext{
${ }^{1}$ For example, the Strategy for Sustainable Development and Inclusive Growth (SDDCI) Niger 2035 and the Economic and Social Development Plan (PDES) 2017-2021).
} 
While migration streams have been shown to be selective in terms of migrants' education (e.g. Docquier and Marfouk 2006) in regard to origin and destination countries, the data in Niger does not allow for a thorough analysis of the main trends and their educational composition.

\section{Data and Methodology}

The multidimensional population projection method (Keyfitz 1985; Rogers 1975) is based on the expansion of the cohort and component projection model. In the multidimensional model, the population is disaggregated by age, sex and by dimensions. The education dimension is ideal for the application of the multidimensional population projection model, as education is mainly acquired at an early age and changes along cohort lines. Therefore, changes in the educational composition of the total population are mostly caused by the depletion (by mortality) of the less educated older cohorts and the entry of younger, more educated cohorts.

Following this approach, we developed EDUDEMPRO, a projection tool with Visual Basic for Applications (VBA). In the model, four dimensions are dynamically projected: age, gender, region of residence and education. In order to run, the model requires the initial population, fertility, mortality and migration according to those characteristics as well as the transition between education categories together with assumptions about the future developments of all determinants.

The initial population is taken from the 2012 Census. We used the 1992, 1998, 2006 and 2012 Demographic and Health Surveys (DHS) data to establish trends and estimates of total- and age-specific fertility rates by level of education and regions. For lack of valid data, the initial mortality data as well as the future mortality assumptions by education for the scenarios originate from global population projections (Lutz et al. 2014), for which mortality tables by level of education were produced for all countries in the world. In the absence of credible data on differential mortality by region, the assumptions are the same for the eight regions of Niger, translating into a difference of 6 years in life expectancy between the highest and the lowest education category for men, and 4 years for women. We used the 2012 Census to build assumptions about the internal mobility in the base year using questions about previous residence. In the trend scenario, mobility rates are quite low, the net migration over a 5-year period varying between $-0.4 \%$ (Diffa) to $0.3 \%$ (Niamey). International migration is omitted in the model, given the absence of reliable data and its high volatility. Nevertheless, the International Organization for Migration (2019) reports marginal net migration values and therefore, it should not influence the size and composition of the population-assuming that this trend continues in the future. For education, each scenario assumes distinct evolution patterns. These assumptions are based on narratives developed with local experts and stakeholders, but also on empirical statistical modelling of past trends. The purpose of statistical modelling is to obtain parameters capturing, on the one hand, the cohort effect (the "trend" in changes between successive age groups) which then makes it possible to establish assumptions about the future, and on the other hand the differences by sex and region. 
Five scenarios were derived from the narratives built in an interactive way and in close collaboration with the members of the project steering committee composed mainly of key persons from the relevant ministries (Planning, health and education ministries), the national statistical institute (INS), and the CAMOS ${ }^{2}$ and $\mathrm{CAPEG}^{3}$ units. The scenarios were based on narratives that were conceptualized in three steps: First, the methodology and rationale of multi-state projections were presented to the committee members in Niamey together with a set of standard scenarios for Niger as a whole (February 2018). At this occasion, we exchanged with the committee on the possible narratives, taking into account the several government plan in the relevant sectors (based on meetings with the education, population, health ministries). With this information, we developed a few scenarios built upon assumptions about the future of fertility, mortality and mobility that were presented together with the projection findings at national and regional levels in June 2018 to the Committee (in Niamey). This lead to a revised version for the steering committee that met in October 2018 in Austria, at the occasion of the visit of a delegation to the International Institute for Applied Systems Analysis (IIASA). Table 1 summarizes both the final narratives and main scenarios assumptions. Deriving narratives and scenarios together with officials faced several challenges that stemmed from the difficulty for officials to abstract from government plans for the purpose of building scenarios, and their expectation for simple fit-all solutions. On the other hand, the committee members show understanding for the limit imposed by the lack of data to estimate some indicators at the regional level.

\section{Main Results}

Niger's population would be growing rapidly in all scenarios (Fig. 1). The 'vicious circle' scenario, which assumes constant fertility (and mortality) in the next 50 years and the stagnation of educational levels, yields a population of 131 million in 2062, six times higher than the 2012 population. In contrast, the 'upturn' scenario, in which fertility declines quickly, enables Niger to reach a population three times lower, i.e. 50 million inhabitants in 2062, which is still more than twice the size of the 2012 population. The other scenarios lead to intermediate future population. The 'trend' scenario translates into an increase of the population up to 106 million in 2062, 91 million in the case of the 'rural development' scenario and 78 million for the 'evolving' scenario. As a consequence of the population momentum and with the exception of the 'upturn' scenario, until 2037, the population varies only slightly between the different alternatives, with hardly more than 3 million difference in total population. Differences in the impact of different scenarios on the total population appear mainly after 2040 .

\footnotetext{
2 A unit in charge of supporting the implementation of the sectorial program for Education and Training (PSEF).

${ }^{3}$ A unit in charge of analysing public policy and assessing government action.
} 


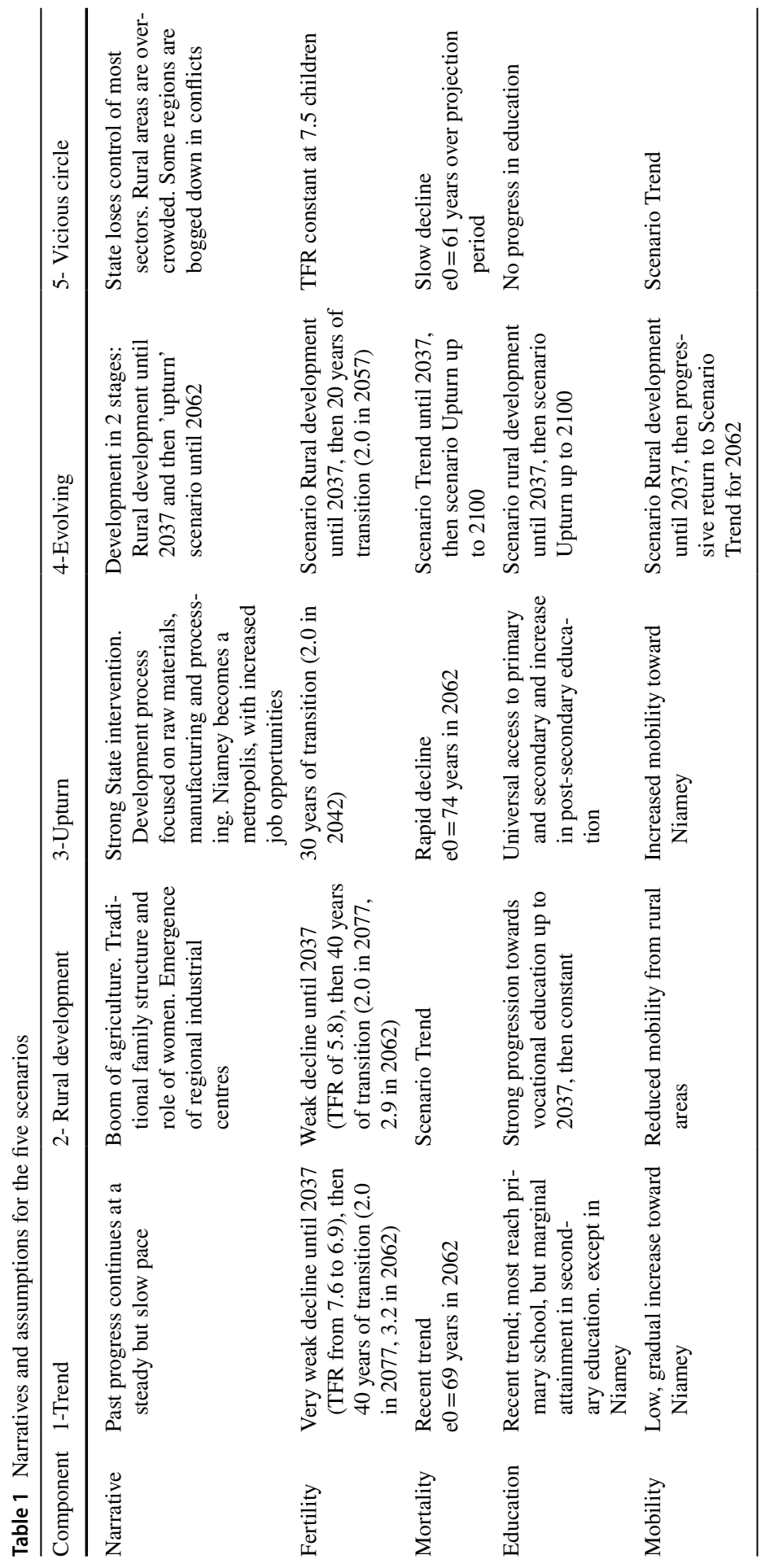




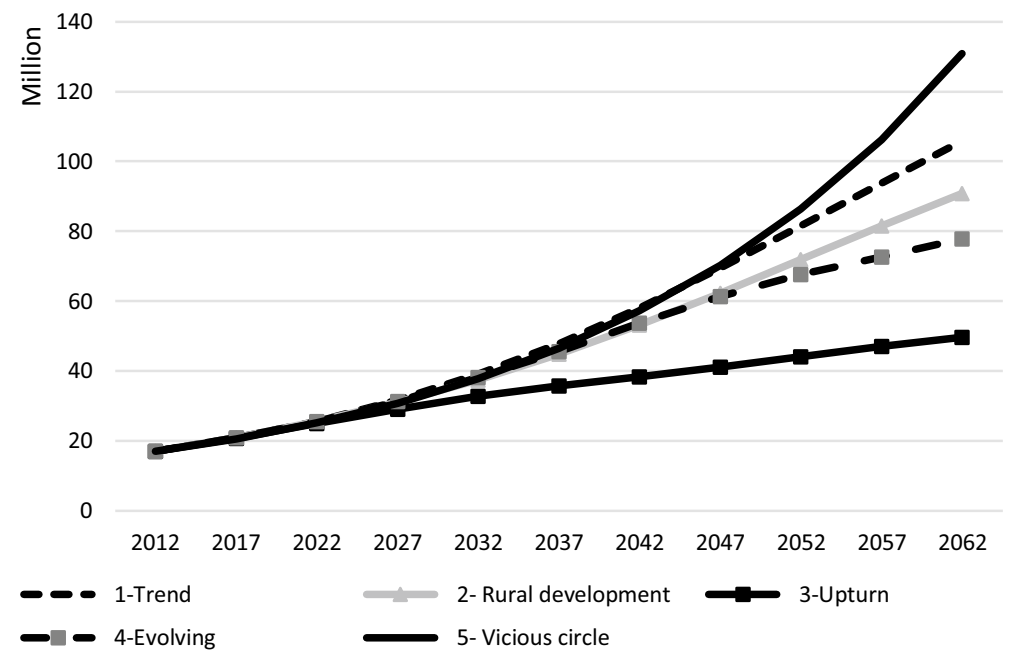

Fig. 1 Niger's total population (in million), several scenarios, 2012-2062. Source: Authors' calculations

At the regional level, in the 'trend' scenario, the population is multiplied by a factor of five and more in all regions between 2012 and 2062 (see Table 2). The demographic future of the capital Niamey is however particular, due to internal migration. The scenario that would generate the smallest population by 2062 would be the 'rural development' scenario, which implies that regions develop the agricultural and agro-industrial sectors and keep their labour force. In this case, the population would increase from 1 to 3.2 million between 2012 and 2062 mainly due to natural increase. On the contrary, the population of Niamey would be substantially increased in the case of the 'upturn' scenario, from 1 million in 2012 to 10.5 million in 2062 as the city would attract the higher educated population of the regions. For other regions, this scenario leads to the lowest growth compared with the others.

The age structure is strongly affected by the different scenarios as shown in Fig. 2 representing the demographic dependency ratio [calculated as the ratio of children (0-14 years old) and elders (65+) on people of working age (15-64)]. In 2012, there were 120 dependents per 100 people of working age. In the 'trend' scenario, this ratio would be roughly stable until 2037, then would decline to 70 by 2062 . This slow decline in the early years can largely be explained by the meagre decrease in fertility rates. In the 'upturn' scenario, fertility begins to decline rapidly at the beginning of the projection period. As a result, the demographic dependency ratio drops drastically and reaches a low of about 40 by 2047. In 2062, the demographic dependency ratio equals 40 both according to the 'evolving' and 'upturn' scenarios, but it takes longer to achieve this level in the former than in the latter, pushing back the time when Niger could benefit from a demographic dividend.

At the regional level, significant gaps exist in the demographic dependency ratio. The Niamey region is in a much better position compared with others, with a ratio of 80 dependents in 2012, while ratios are higher than 110 in all other regions. Niamey retains this advantage throughout the projection. In the 'trend' scenario, the ratio 
Table 2 Total population, Niger and regions, several scenarios, 2012-2062. Source: Authors' calculations

\begin{tabular}{|c|c|c|c|c|}
\hline \multirow[t]{2}{*}{ Country/region } & \multirow[t]{2}{*}{ Scenario } & \multicolumn{3}{|l|}{ Year } \\
\hline & & 2012 & 2037 & 2062 \\
\hline \multirow[t]{5}{*}{ Niger } & 1-Trend & $17,117,679$ & $47,819,624$ & $105,751,587$ \\
\hline & 2-Rural development & & $44,855,780$ & $90,866,429$ \\
\hline & 3-Upturn & & $35,795,349$ & $49,647,176$ \\
\hline & 4-Evolving & & $45,683,323$ & $77,909,210$ \\
\hline & 5-Vicious circle & & $46,571,291$ & $130,795,211$ \\
\hline \multirow[t]{5}{*}{ Agadez } & 1-Trend & 487,134 & $1,432,205$ & $2,772,626$ \\
\hline & 2-Rural development & & $1,176,702$ & $2,282,827$ \\
\hline & 3-Upturn & & $1,174,561$ & $1,862,261$ \\
\hline & 4-Evolving & & $1,244,425$ & $2,224,559$ \\
\hline & 5-Vicious circle & & $1,402,357$ & $3,274,483$ \\
\hline \multirow[t]{5}{*}{ Diffa } & 1-Trend & 592,429 & $1,364,766$ & $2,291,890$ \\
\hline & 2-Rural development & & $1,303,226$ & $2,355,997$ \\
\hline & 3-Upturn & & $1,014,614$ & $1,032,594$ \\
\hline & 4-Evolving & & $1,329,019$ & $1,843,367$ \\
\hline & 5- Vicious circle & & $1,332,829$ & $2,753,854$ \\
\hline \multirow[t]{5}{*}{ Dosso } & 1-Trend & $2,036,604$ & $5,789,076$ & $12,466,899$ \\
\hline & 2-Rural development & & $5,409,263$ & $11,174,245$ \\
\hline & 3-Upturn & & $4,263,839$ & $5,334,540$ \\
\hline & 4-Evolving & & $5,544,826$ & $8,502,827$ \\
\hline & 5-Vicious circle & & $5,749,085$ & $16,393,102$ \\
\hline \multirow[t]{5}{*}{ Maradi } & 1-Trend & $3,399,086$ & $10,284,710$ & $24,142,186$ \\
\hline & 2-Rural development & & $9,689,505$ & $21,143,220$ \\
\hline & 3-Upturn & & $7,265,583$ & $9,045,657$ \\
\hline & 4-Evolving & & $9,774,854$ & $15,851,226$ \\
\hline & 5- Vicious circle & & $9,901,481$ & $30,580,724$ \\
\hline \multirow[t]{5}{*}{ Niamey } & 1-Trend & $1,025,732$ & $2,778,529$ & $8,210,359$ \\
\hline & 2-Rural development & & $2,232,320$ & $3,191,570$ \\
\hline & 3-Upturn & & $3,161,934$ & $10,511,297$ \\
\hline & 4-Evolving & & $2,285,538$ & $9,533,746$ \\
\hline & 5-Vicious circle & & $2,537,575$ & $5,895,375$ \\
\hline \multirow[t]{5}{*}{ Таһоиа } & 1-Trend & $3,322,215$ & $8,886,910$ & $19,039,651$ \\
\hline & 2-Rural development & & $8,608,807$ & $17,477,879$ \\
\hline & 3-Upturn & & $6,457,027$ & $7,588,253$ \\
\hline & 4-Evolving & & $8,704,962$ & $14,250,011$ \\
\hline & 5-Vicious circle & & $8,547,808$ & $23,301,190$ \\
\hline \multirow[t]{5}{*}{ Tillaberi } & 1-Trend & $2,720,718$ & $7,439,937$ & $15,187,120$ \\
\hline & 2-Rural development & & $7,131,153$ & $14,334,805$ \\
\hline & 3-Upturn & & $5,357,019$ & $5,846,447$ \\
\hline & 4-Evolving & & $7,297,179$ & $11,105,063$ \\
\hline & 5- Vicious circle & & $7,530,563$ & $21,359,424$ \\
\hline
\end{tabular}


Table 2 (continued)

\begin{tabular}{lllrr}
\hline Country/region & Scenario & \multicolumn{2}{l}{ Year } & \\
\cline { 3 - 5 } & & 2012 & 2037 & 2062 \\
\hline Zinder & 1-Trend & $3,533,761$ & $9,843,492$ & $21,640,856$ \\
& 2-Rural development & & $9,304,804$ & $18,905,886$ \\
& 3-Upturn & & $7,100,772$ & $8,426,126$ \\
& 4-Evolving & & $9,502,520$ & $14,598,410$ \\
& 5- Vicious circle & & $9,569,594$ & $27,237,058$ \\
\hline
\end{tabular}

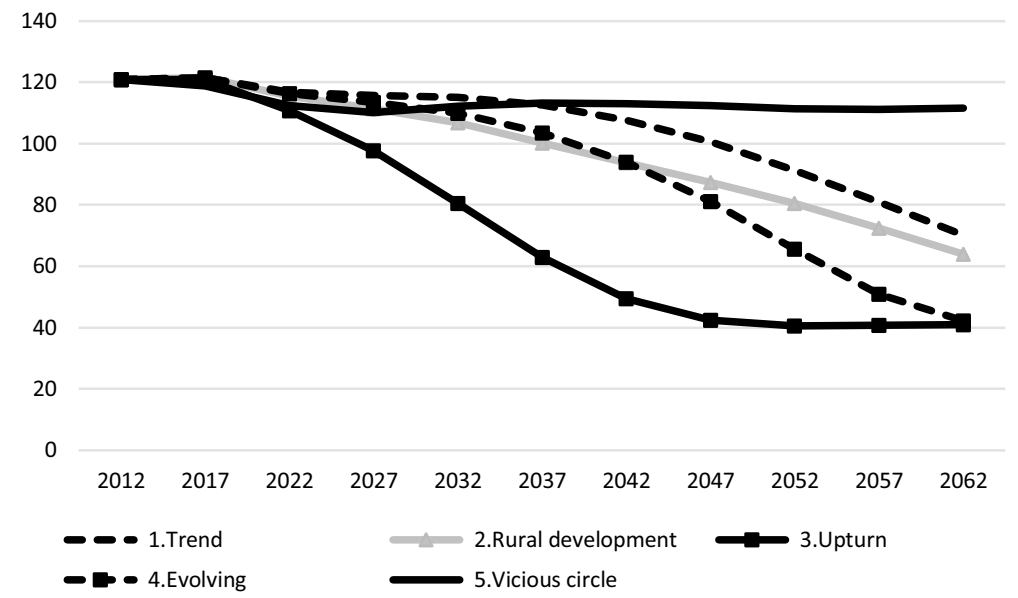

Fig. 2 Projected demographic dependency ratio, 2012-2062, several scenarios, Niger. Source: Authors' calculations

drops to 40 in 2062, while it still oscillates between 60 and 80 in the other regions. This difference can be explained firstly by an already lower fertility in Niamey, and secondly by its migratory advantage, the region having a net positive net migration with a large population of young adults.

The significant potential changes we have highlighted in terms of total population are both the consequence and the cause of profound changes in the educational levels of the population. Figure 3 decomposes the projected population by educational attainment.

Apart from the 'vicious circle' scenario, the share of the population with an incomplete primary education or less decreases considerably among the population aged 15 and over, from $83 \%$ in 2012 to $35-64 \%$ in 2037 and to $11-37 \%$ in 2062 depending on the scenario. This decrease goes hand in hand with an increase in the population with secondary or higher education, already within the 'trend' scenario (35\% in 2062) but even more so in the other scenarios and especially in the 'upturn' scenario: More than 50\% of 25-39 year-old would have a secondary 

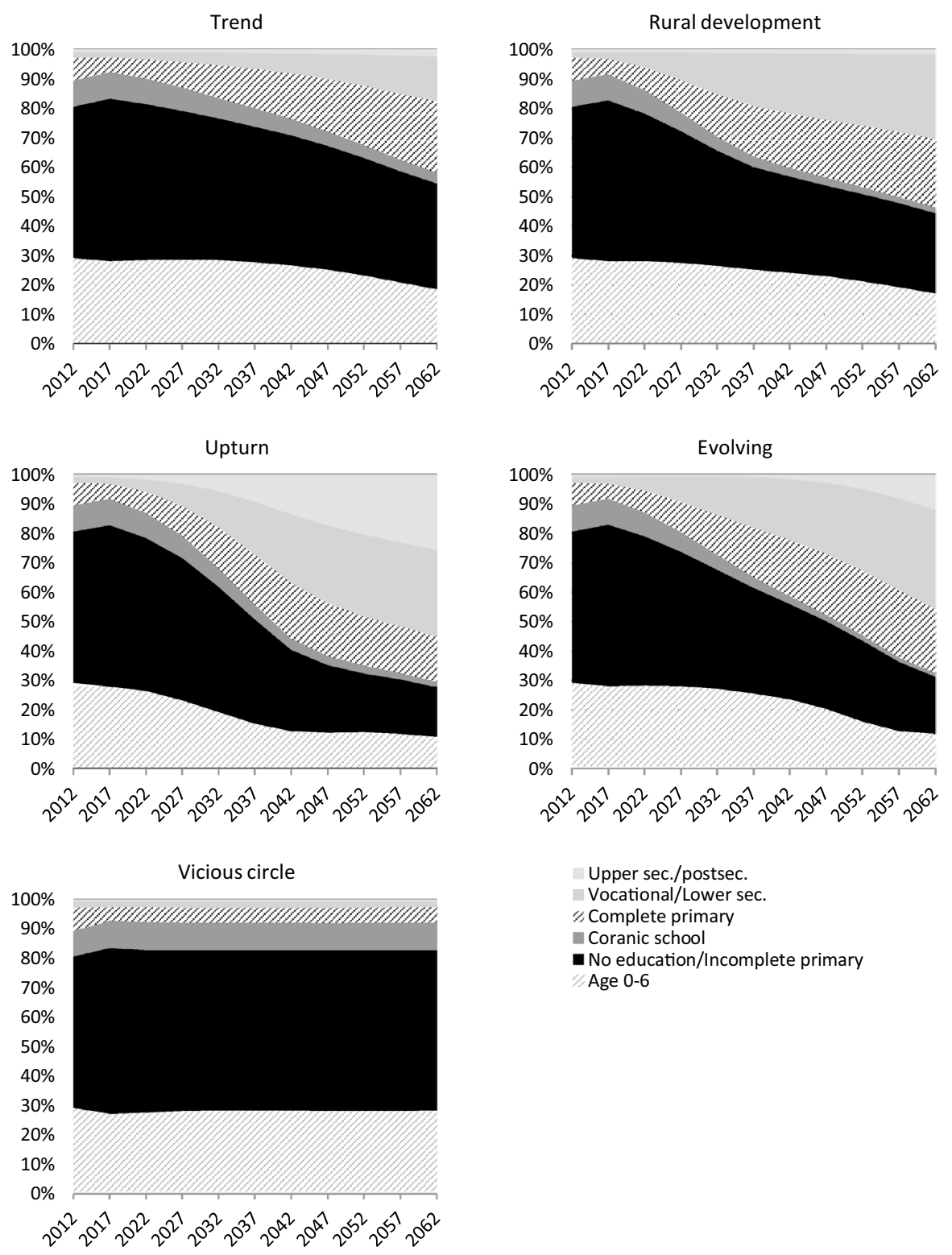

Fig. 3 Niger's population by level of education, 2012-2062, several scenarios. Source: Authors' calculations

or higher education in 2037 and more than $85 \%$ in 2062. When comparing cohorts, the difference is minimal in 2012 due to the stall in education progress: only $6 \%$ of 25-39 year olds have a secondary or higher education compared to $4 \%$ for the older generation aged 40 and over. In contrast, in 2037, the difference would widen with increased investment in education. For example, in the 'rural development' scenario, 
only $10 \%$ of those aged 40 and over would have a secondary or higher education - as they would not benefit from the progress envisaged by this scenario-compared to $42 \%$ of the 25-39 age group. By 2062, progress is visible in both generations. The 25-39 age group representing the most productive part of the population could play a significant role in the development of the country. However, the other side of the coin is that like population, education change has a large momentum and there would be for a long time a substantial proportion of the population with low levels of education, between 40 and 64\% in 2037 and 12 and 37\% in 2062 (all scenarios considered except 'vicious circle'). Moreover, this population would continue to increase in absolute terms, with the exception of the 'upturn' scenario, even if at a slower rate than in the past. The annual growth rate will be $+1 \%$ in the 'evolving' scenario, $+2 \%$ in the 'rural development' scenario and $+3 \%$ in the trend scenario.

The education momentum is also visible in the eight regions where the projected educational attainment varies according to the scenarios and to the starting situation. The educational structure of the Niamey region is different depending on whether it attracts the highest educated population of the other regions ('trend', 'upturn' and 'evolving' scenarios), if the level of education does not progress ('vicious circle' scenario) or if the educated population stays in the origin region ('rural development' scenario). If the 'trend' scenario allows for a noticeable increase in the educational attainment in all regions, this will not be substantial until 2037. For example, the proportion of the population age $15+$ without a complete primary education decreases by $74 \%$ to $52 \%$ in 2037 , then to $25 \%$ in 2062 . The intensification of efforts would make it possible to reduce this share significantly but not in the near future. This results in an increase in the population with lower secondary education or higher, which is faster for the 20-39 age group than for the $40+$.

\section{Conclusion}

With demography and education having a strong inertia, Niger will have to face a strong demographic growth in the short and the medium term. Indeed, even in the case of a rapid decline of the fertility, several decades will be necessary before the population stabilizes. At the same time, the education levels of a majority of the population will remain low. The inevitability of these facts calls for swift and radical action to be able to provide the people of Niger with a better quality of life. The regions will also see their development seriously influenced by the present conditions. The scenarios show that some inequalities in population or education may be accentuated or reduced in the future.

The different findings point at the necessity of three different policy priorities: First of all, focus on combing population growth, possibly through awareness campaigns and increase in the availability of family planning; second, increase investments in education, that could both generate a declining fertility and increase the productivity of both men and women in the country. Third, the regions have different need and therefore those should be taken into account.

'Education does not jump', this sentence of economist Schumacher (1973) simply illustrates the need to invest today in mass and quality education. Any child who passes through the meshes of education or who receives an inadequate education, 
not allowing him/her to be literate or to integrate into the labour market, will keep this status over his/her lifetime. It should be noted that increased in the quantity of education should not occur at the expense of quality.

Acknowledgements Open access funding provided by International Institute for Applied Systems Analysis (IIASA).

Funding The study was funded by UNICEF.

Open Access This article is licensed under a Creative Commons Attribution 4.0 International License, which permits use, sharing, adaptation, distribution and reproduction in any medium or format, as long as you give appropriate credit to the original author(s) and the source, provide a link to the Creative Commons licence, and indicate if changes were made. The images or other third party material in this article are included in the article's Creative Commons licence, unless indicated otherwise in a credit line to the material. If material is not included in the article's Creative Commons licence and your intended use is not permitted by statutory regulation or exceeds the permitted use, you will need to obtain permission directly from the copyright holder. To view a copy of this licence, visit http://creativecommons.org/licen ses/by/4.0/.

\section{References}

Bongaarts, J. (2010). The causes of educational differences in fertility in sub-Saharan Africa. Vienna Yearbook of Population Research (Vol. 8, pp. 31-50). New York: The Population Council.

Census 2012-Recensement Général de la Population et de l'Habitat (RGPH) de 2012. Niamey: INS. Disponible à : https://www.stat-niger.org/statistique/file/RGPH2012/Resultats_globaux_definitifs _RGPH2012.pdf. (consulté le 26/4/2019)

Docquier, F., \& Marfouk, A. (2006). International migration by educational attainment, 1990-2000. In C. Özden (Ed.), International migration, remittances, and the brain drain (pp. 151-200). Washington, D.C.: World Bank.

Goujon, A., Marois, G., Sabourin, P. (Forthcoming). Démographie et Education au Niger: Une Analyse Prospective. Niamey: UNICEF et Ministère du plan, Gouvernement du Niger.

International Organization for Migration (2019). Migration Data Portal-Niger. Available at https:// migrationdataportal.org/data.

Niger Demographic and Health Survey (1992). Columbia, MD: Direction de la Statistique et des Comptes Nationaux/Niger and Macro International

Niger Demographic and Health Survey (1998). Calverton, MD: Care International/Niger and Macro International.

Niger Demographic and Health Survey (2006). Calverton, MD: INS/Niger et Macro International.

Niger Demographic and Health Survey (2012). Calverton, MD: INS/Niger et ICF International.

Keyfitz, N. (1985). Applied Mathematical Demography (2nd ed.). New York: Springer.

Kraval, Ø. (2002). Education and fertility in sub-Saharan africa: Individual and community effects. Demography, 39(2), 233-250.

Lutz, W., Butz, W. P., \& Samir, K. C. (2014). Population and Human Capital in the 21st Century. Oxford: Oxford University Press.

Rogers, A. (1975). Introduction to multiregional mathematical demography. New York: Wiley.

Schumacher, E. F. (1973). Small is beautiful. A study of economics as if people mattered. London: Blond \& Briggs.

Spoorenberg, T., \& Issaka Maga, H. (2018). Fertility compression in Niger: A study of fertility change by parity (1977-2011). Demographic Research, 39, 685-700.

United Nations (2019). Department of Economic and Social Affairs, Population Division. 2019. World Population Prospects: The 2019 Revision, DVD Edition.

Publisher's Note Springer Nature remains neutral with regard to jurisdictional claims in published maps and institutional affiliations. 